\title{
Comparison of aerosol lidar retrieval methods for boundary layer height detection using ceilometer aerosol backscatter data
}

\author{
Vanessa Caicedo $^{1}$, Bernhard Rappenglück ${ }^{1}$, Barry Lefer $^{2}$, Gary Morris $^{3}$, Daniel Toledo ${ }^{4}$, and Ruben Delgado ${ }^{5}$ \\ ${ }^{1}$ Department of Earth and Atmospheric Sciences, University of Houston, Houston, TX, USA \\ ${ }^{2}$ Tropospheric Composition Program, Earth Science Division, NASA Headquarters, Washington, DC, USA \\ ${ }^{3}$ School of Natural Sciences, Saint Edward's University, Austin, TX, USA \\ ${ }^{4}$ Department of Physics, University of Oxford, Oxford, UK \\ ${ }^{5}$ Joint Center for Earth Systems Technology, University of Maryland Baltimore Country, Baltimore, MD, USA
}

Correspondence to: Vanessa Caicedo (caicedo.vanessa@gmail.com)

Received: 11 October 2016 - Discussion started: 17 October 2016

Revised: 27 January 2017 - Accepted: 7 March 2017 - Published: 26 April 2017

\begin{abstract}
Three algorithms for estimating the boundary layer heights are assessed: an aerosol gradient method, a cluster analysis method, and a Haar wavelet method. Over 40 daytime clear-sky radiosonde profiles are used to compare aerosol backscatter boundary layer heights retrieved by a Vaisala CL31 ceilometer. Overall good agreement between radiosonde- and aerosol-derived boundary layer heights was found for all methods. The cluster method was found to be particularly sensitive to noise in ceilometer signals and lofted aerosol layers ( $48.8 \%$ of comparisons), while the gradient method showed limitations in low-aerosol-backscatter conditions. The Haar wavelet method was demonstrated to be the most robust, only showing limitations in $22.5 \%$ of all observations. Occasional differences between thermodynamically and aerosol-derived boundary layer heights were observed.
\end{abstract}

\section{Introduction}

The boundary layer (BL) is defined as the lowest layer in the atmosphere directly influenced by the earth's surface. The boundary layer reacts to surface forcings such as evaporation and transpiration, heat transfer, frictional drag, and terrainproduced air flows within a timescale of an hour or less (Stull, 1988). Other forcings such as pollutant emission, in particular $\mathrm{PM}_{2.5}$ (particulate matter), can enhance the stability of the BL and decrease the boundary layer height (Petäjä et al., 2016). Above the boundary layer is the free troposphere (FT) acting as a cap to the BL. Convection and turbu- lence created by surface heating lead to the gradual growth of the BL starting at sunrise, mixing gaseous compounds and particles within the convective mixing layer (ML). Above the ML is the stable entrainment zone (EZ), where the FT is entrained downward into the ML, and ML thermals overshoot upward into the EZ (Stull, 1988; Toledo et al., 2014). The ML begins to decay as surface heating and turbulence decrease, eventually creating a near-surface nocturnal stable layer (NSL). Leftover constituents from the daytime ML form the residual layer (RL) above the NSL (Stull, 1988). More complex BL structures can also form in specific environmental conditions such as multiple stable layers and internal boundary layers (Garratt, 1990; Stull, 1988).

The determination of the BL height (BLH) is vital in air pollution studies as it determines the extent of vertical mixing of pollutants. While this is a key parameter in air pollution modeling and air quality studies, continuous monitoring of the BL is rarely available. The most common way of retrieving the BLH has been with the use of radiosondes. However, radiosondes are seldom launched more than a few times a day except during extensive and costly scientific campaigns in which they are only launched for the duration of the campaign. Apart from a few occasions (e.g., André and Mahrt, 1982; Berman et al., 1999; Day et al., 2010), NSL measurements are particularly uncommon since most radiosonde launches are performed during daytime ML hours. In recent years, remote-sensing techniques such as light detection and ranging (lidar), radio acoustic sounding systems (RASS), and sonic detection and ranging (sodar) systems have allowed for 
the continuous monitoring of the BL (Cohn and Angevine, 2000; Schäfer et al., 2011; Seibert et al., 2000; Emeis et al., 2004, 2006, 2012; Eresmaa et al., 2006; Baars et al., 2008; McKendry et al., 2009; Muñoz and Undurraga, 2010; Haman et al., 2012; Milroy et al., 2012; Compton et al., 2013; Scarino et al., 2014; Wiegner and Gasteiger, 2015; Uzan et al., 2016). Ceilometers in particular offer a low-maintenance and low-cost solution to constantly monitoring the ML using aerosol backscatter while also facilitating the monitoring of the nocturnal stable layer, internal aerosol layers, and the nighttime residual layer (Haman et al., 2012, 2014; Pandolfi et al., 2013; Peña et al., 2013). The extensive data set from continuous lidar measurements results in the need for determining the most reliable and accurate method to be used in automated retrievals.

In order to evaluate the retrieval of BLHs from aerosol lidars, we tested three distinct methods. Previous studies have evaluated retrieval methods such as the study done by Haeffelin et al. (2012) reviewing various methods (automated and semi-automated) across three lidars. This study in turn evaluates a gradient method, a Haar wavelet method, and a cluster analysis method to retrieve BLHs using aerosol backscatter measured by a Vaisala CL31 ceilometer located in an urban environment. These BLHs are then compared to radiosondederived BLHs for validation in order to arrive at the automated algorithm with the least manual inspection required. The effect of cloud signals on the BLH retrieval is also observed in all retrieval methods tested and discussed in this study.

\section{Data and instrumentation}

This study uses Vaisala CL31 ceilometer data and radiosonde profiles measured at the University of Houston (UH) main campus. UH main campus is located about $70 \mathrm{~km}$ northwest of the Gulf of Mexico and $5 \mathrm{~km}$ southeast of downtown Houston. The UH CL31 was mounted atop a trailer approximately $3.5 \mathrm{~m}$ above ground, and radiosonde launches were performed next to the CL31 trailer. A total of 85 radiosonde profiles from the Tropospheric Ozone Pollution Project were analyzed for this study, but only profiles corresponding to cloud-free aerosol backscatter vertical profiles were used for the BLH detection comparison. The Tropospheric Ozone Pollution Project seeks to understand the combination of pre- and post-frontal conditions ideal for high-ozone events in the Houston area using ozonesonde and radiosonde profiles. The project is focused in the fall and spring seasons, when high-ozone events are frequent. This results in the data set used containing $\sim 43 \%$ of launches during cloudy prefrontal conditions, with a remaining 48 cloud-free launches in post-frontal clear skies. Launches between January 2011 and March 2015 are used, with the highest frequency in the months of May, June, September, and October. All launches occurred between 06:00 and 17:00 CST, with most radioson-

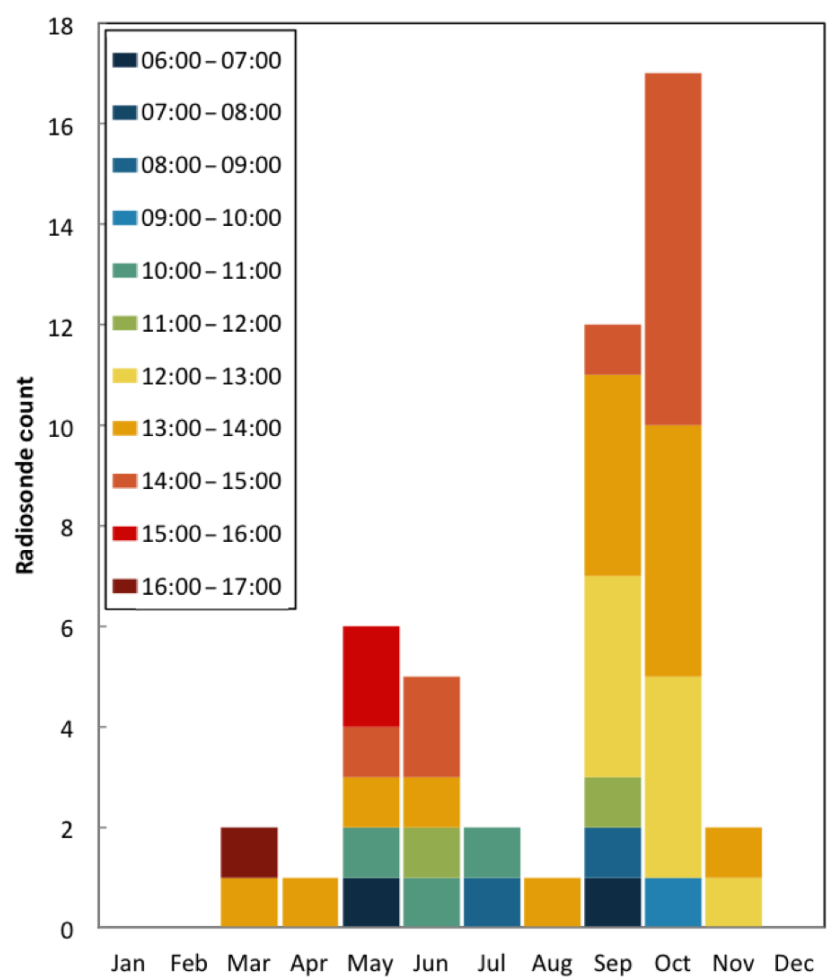

Figure 1. Cloud-free radiosonde launches used for the method comparison specified by the time of launch in CST.

des launching during convective ML hours between 13:00 and 15:00 CST (Fig. 1). The effect of cloud signals is analyzed separately for each method in Sect. 4.4. In addition, this data set includes ceilometer and radiosonde data from the NASA DISCOVER-AQ (Deriving Information on Surface conditions from Column and Vertically Resolved Observations Relevant to Air Quality) Texas campaign in September 2013 .

\subsection{Vaisala CL31}

The Vaisala CL31 ceilometer operates at a wavelength of 905 nanometers (nm) using an indium gallium arsenide laser diode (InGasAs) system with a $1.2(\mathrm{~mJ})$ pulse for $110(\mathrm{~ns})$ and mean pulse repetition rate of $8192(\mathrm{~Hz})$. It uses a singlelens design to both transmit and receive light signals. This design reduces the optical crosstalk between transmitter and receiver and in turn increases the signal-to-noise ratio. A beam splitter gives full overlap of the transmitter and receiver field of view at an altitude of $70 \mathrm{~m}$ (Münkel et al., 2007).

The backscatter coefficient $\beta(x, \lambda)$ or the backscattering cross section per unit volume is related to the received power with the following formula:

$P(x, \lambda)=\frac{c}{2 x^{2}} P_{0} A \eta O(x) \Delta t \times \beta(x, \lambda) \tau^{2}(x, \lambda)+B$,

where $P$ is the optical power received by the ceilometer from distance $x, c$ is the speed of light, $\Delta t$ is the pulse duration, 
$P_{0}$ is the average laser power during pulse, $A$ is the area of receiver optics, $\eta$ is the receiver optics' efficiency, $O(x)$ is the range-dependent overlap integral between beam transmitted and received, $\tau(x, \lambda)$ is the transmittance of the atmosphere between lidar and volume, $\lambda$ is the wavelength of the emitted laser pulse, $x$ is the distance between lidar and scattering volume, and $B$ is the sum of electronic and optical background noise (Weitkamp, 2005). The CL31 returns profiles which are proportional and close to the attenuated backscatter profiles $\beta(x, \lambda) \tau^{2}(x, \lambda)$. For text-shortening reasons and because at the CL31 wavelength the aerosol backscatter coefficient dominates over the molecular backscatter coefficient inside the BL and clouds, these profiles are called aerosol backscatter profiles in this paper.

Aerosol backscatter profiles with signals from clouds, rain, or fog are identified as signals higher than $2000 \times$ $10^{-9} \mathrm{~m}^{-1} \mathrm{sr}^{-1}$ and were not used for this BLH comparison (Kamp and McKendry, 2010).

The CL31 can measure aerosol backscatter up to $7500 \mathrm{~m}$. However, the CL31 does not record these signals but instead only accumulates aerosol backscatter intensity every $16 \mathrm{~s}$ with a maximum height of 4500 and $10 \mathrm{~m}$ resolution. The CL31 ran with firmware v1.7 and noise_h2 on. For morein-depth information about the instrument see Münkel et al. (2007) and Kotthaus et al. (2016).

\section{2 iMet radiosondes}

Radiosondes launched at UH main campus are International Met Systems Incorporated model iMet-1. iMet-1 radiosondes return GPS (Global Positioning System) location, GPS altitude, wind speed and direction, pressure, temperature, and relative humidity with a $1 \mathrm{~Hz}$ sampling rate using a $403 \mathrm{MHz}$ transmitter. Radiosondes used here have a resolution of $0.01 \mathrm{hPa}$, a response time of $1 \mathrm{~s}$, and an accuracy of $0.5 \mathrm{hPa}$ for pressure measurements. Temperature sensing has a resolution of $0.01^{\circ} \mathrm{C}$, accuracy of $0.2{ }^{\circ} \mathrm{C}$, and response time of $2 \mathrm{~s}$. The humidity sensors for the radiosondes have a resolution of less than $0.1 \%$, accuracy of $5 \%$, and response time of $2 \mathrm{~s}$. Average ascent rate for all launches was about $5 \mathrm{~m} \mathrm{~s}^{-1}$.

A total of 85 launches were analyzed for this study, but only launches corresponding to cloud-free aerosol backscatter vertical profiles are used in the retrieval method comparison. This results in 48 launches between March 2012 and March 2015, with only four launches before 09:00, six before midday, and the remaining 38 launches after midday, with the highest number of launches between 12:00 and 14:00 CST (see Fig. 1).

\section{Boundary layer height retrieval methods}

All aerosol-derived BLH methods presented here are based on two assumptions: (1) the BL contains a somewhat constant concentration of aerosols due to convective and turbu- lent mixing, and (2) the clean FT above will create a negative gradient in aerosol backscatter from higher concentrations within the BL towards lower concentrations in the FT. The local maximum of this gradient is identified as the top of the BL (Steyn et al., 1999). Thermodynamic radiosonde BLHs are calculated using a skew-T-log-P diagram method and are compared to aerosol-derived BLHs calculated from aerosol backscatter profiles closest in time to the radiosonde launch but not exceeding $10 \mathrm{~min}$ before or after the launch.

\subsection{Skew-T-log-P diagram for radiosonde boundary layer heights}

A stable BL is characterized by having an environmental lapse rate greater than a moist/dry adiabatic lapse rate (Fig. 2a), while an unstable boundary layer is identified by having a dry adiabatic lapse rate greater than the environmental lapse rate (Fig. 2b). Stable profiles BLHs are identified as the top of the shallow stable layer as seen as a strong positive vertical gradient change in temperature and a strong negative gradient in dew point temperature profiles (Fig. 2a). BLHs during unstable conditions are identified as the base of the stable EZ (i.e., temperature inversion) where the temperature profile intersects dry adiabatics and/or where relative humidity or dew point temperature profiles sharply decrease as seen in the skew-T-log-P diagram in Fig. 2b (Stull, 1988; Kovalev and Eichinger, 2004; Haman et al., 2012). A previous study by Haman et al. (2012) found a correlation coefficient of 0.96 during unstable conditions and 0.91 during stable conditions when comparing ceilometer- and radiosonde-derived BLHs (both manually) using the skew-T-log-P method.

\subsection{Vaisala Corporation aerosol backscatter gradient}

The Vaisala Corp. BL Matlab v3.7 algorithm is used in this study. This algorithm finds negative gradients with increasing altitude in aerosol backscatter profiles following the assumptions discussed in Sect. 3. A $10 \mathrm{~min}$ and $120 \mathrm{~m}$ height averaging is applied to the profile along with a temperature dependence curve of -10 as recommended by Vaisala Corporation (C. Münkel, personal communication, September 2013) due to the tendency of the CL31 having a curvature in aerosol backscatter profiles with increasing internal temperatures. The temperature correction of -10 is an algorithm setting that adjusts the shape and curve of temperatureaffected aerosol backscatter profiles with negligible effects on aerosol layer detection (Münkel et al., 2007; Vaisala Oyj, 2011; C. Münkel, personal communication, April 2016).

The change in aerosol backscatter with height $(\mathrm{d} \beta / \mathrm{d} x)$ is calculated by the algorithm, which then finds the three largest negative gradients with a minimum aerosol backscatter change of $200 \times 10^{-9} \mathrm{~m}^{-1} \mathrm{sr}^{-1}$. This study uses a minimum gradient height setting of $30 \mathrm{~m}$ along with a sensitivity setting of $15 \%$, which requires a $15 \%$ change in the relative aerosol backscatter in the vicinity of the possible BLH. 

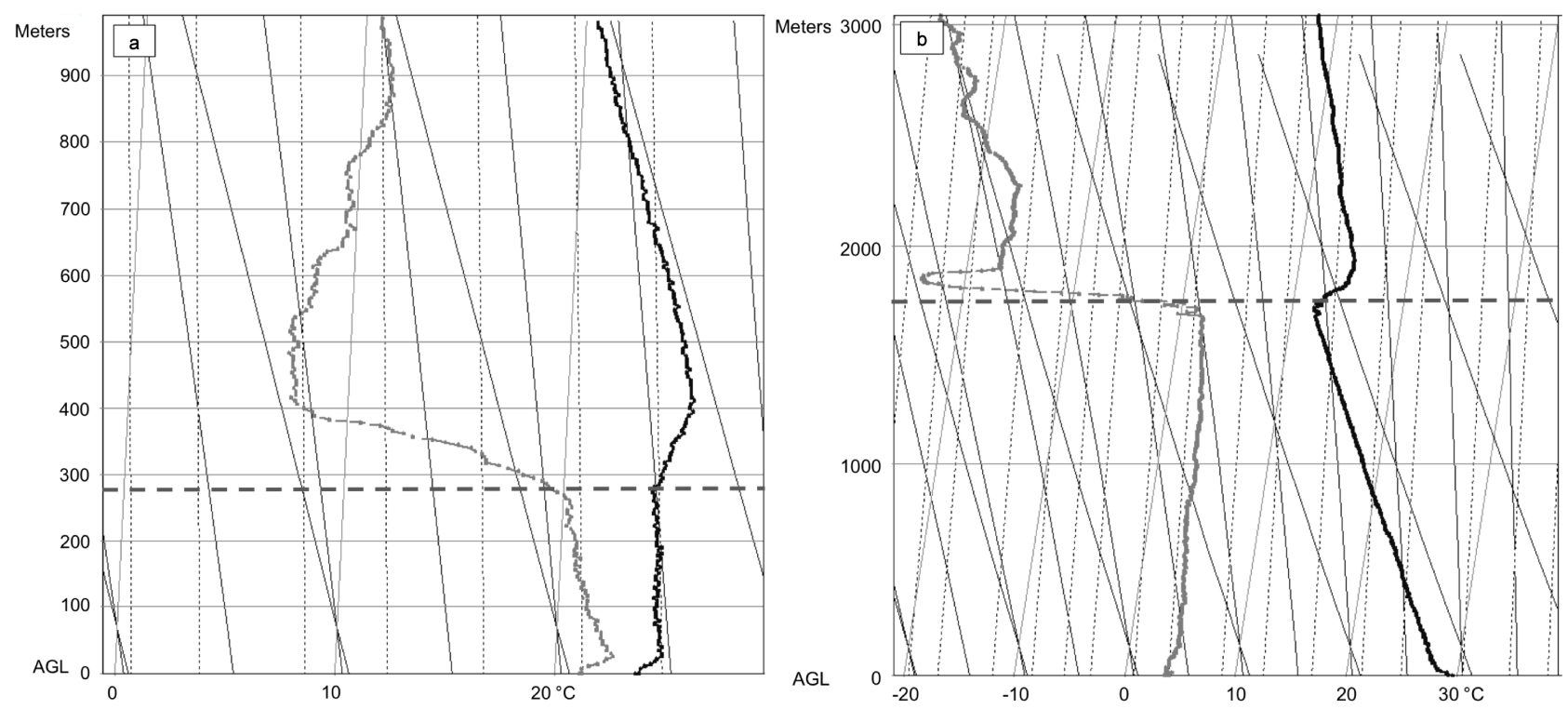

Figure 2. Skew-T-log-P method for BLH detection using temperature (black) and dew point temperature (grey) for (a) stable and (b) unstable conditions with BLH shown as a grey dashed line. Soundings from 26 September 2013 at 06:10 CST (a) and 4 May 2014 at 15:40 CST (b).

The largest of the negative gradients is usually defined as the BL (Münkel et al., 2007; Vaisala Oyj, 2011); however, the largest negative gradient does not always correspond to the BL (see Sect. 4). Therefore, a manual analysis of the algorithm's three resulting layers (Fig. 3) is required in order to prevent the incorrect identification of other aerosol layers. The algorithm gives three maximum negative gradients every $1 \mathrm{~min}$, of which one is manually chosen as the BLH. These are then averaged to $10 \mathrm{~min}$ for radiosonde comparison. The manual approach required to select one of the three maximum negative gradients as the BLH requires a priori knowledge of typical nocturnal and daytime BL heights. In addition, this manual selection analysis can be time-consuming, especially when long-term lidar data are evaluated.

\subsection{Cluster analysis}

This method uses variations in the measured aerosol vertical profiles for BLH calculations. The BLH is typically identified as the (temporal) variance local maximum based on the assumption that the EZ contains high aerosol variability due to clean air masses from the free atmosphere mixing with masses from the BL. The center of the EZ corresponds to the top of the BL (Hooper and Eloranta, 1986; Stull, 1988; Piironen and Eloranta, 1995).

Toledo et al. (2014) tested nonhierarchical and hierarchical cluster analysis on lidar-retrieved vertical aerosol distribution and its variance. Both cluster methods were found to be reliable in calculating BLHs but with a tendency to overestimate the BLH compared to aerosol backscatter gradient methods. This overestimation was attributed to the gradient methods identifying the BLH as a significant decrease in signal, while

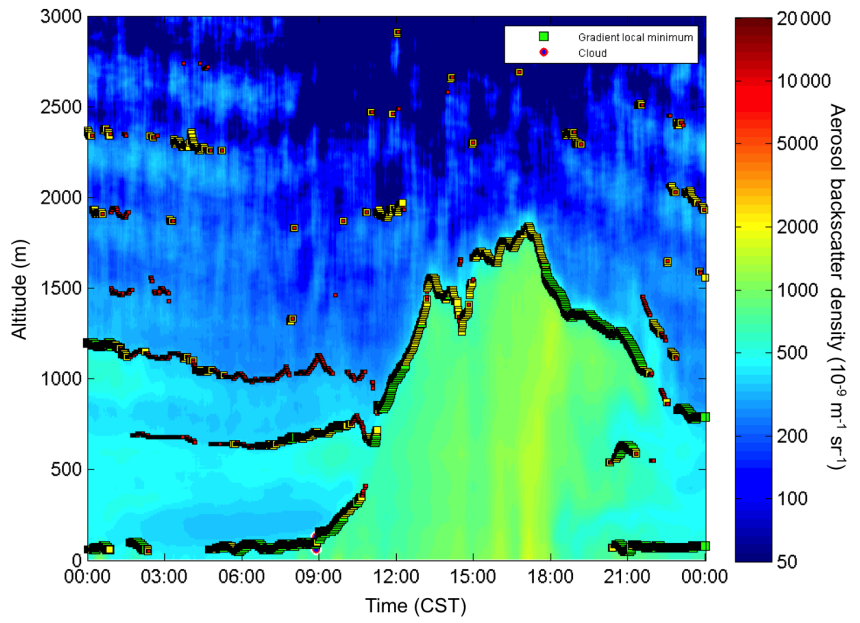

Figure 3. Aerosol backscatter time series for 24 October 2013. Three gradient local minimums are plotted for each $1 \mathrm{~min}$ aerosol backscatter profile.

the cluster method uses a local maximum in variance corresponding to the middle of the EZ. The maximum negative gradient does not always correspond to the local maximum in variance; in these cases the greater the EZ depth, the greater the overestimation of the BLH (Toledo et al., 2014). Nevertheless, the cluster method offers a unique BLH, whereas aerosol gradient methods can give multiple results.

\section{Data processing for cluster analysis and application}

Due to low signal-to-noise ratio and noise-generated artifacts, both a 10 min moving time average and moving height 
Table 1. Averaging heights by height range used on aerosol backscatter profiles for cluster and wavelet methods.

\begin{tabular}{lr}
\hline Altitude range & Averaging height \\
\hline $10-490 \mathrm{~m}$ & $70 \mathrm{~m}$ \\
$500-990 \mathrm{~m}$ & $330 \mathrm{~m}$ \\
$1000-1990 \mathrm{~m}$ & $590 \mathrm{~m}$ \\
$2000-4500 \mathrm{~m}$ & $690 \mathrm{~m}$ \\
\hline
\end{tabular}

average were applied to raw aerosol backscatter profiles. Height averages were applied as seen in Table 1. These averaging settings were chosen as they created the most reliable cluster-calculated BLHs, similar to findings in averaging done for gradient methods (Emeis et al., 2008a, b). Because the range correction needed to invert Eq. (1) increases noise in aerosol backscatter profiles with height, lower averaging was applied to lower altitudes, while higher averaging was applied to higher altitudes (Table 1). This study found that these averaging settings worked best on most aerosol profiles and aerosol conditions. Typically, lower averaging than that listed in Table 1 caused artificial variance peaks, while greater averaging smoothed out variance peaks in the aerosol backscatter profiles. The moving time average also leads to more profiles containing cloud signals; therefore only 45 comparisons were found to be valid for this method.

Variance $V$ as a function of height $z$ were then calculated from cloud-free profiles $R$ using the following formula (Hooper and Eloranta, 1986):

$V(z)=\frac{1}{N-1} \sum_{i=1}^{N}\left[R\left(z, t_{i}\right)-\bar{R}(z)\right]^{2}$,

where $R\left(z, t_{i}\right)$ is the averaged lidar aerosol backscattered signal at time $t_{i}$ and height $z$, and $\bar{R}$ is the averaged profile from $N$ number of profiles corresponding to $10 \mathrm{~min}$.

$K$-means clustering can then be applied to identify BLHs. $K$-means is a data-partitioning algorithm that assigns standardized 3-D point observations (height range of profile, aerosol backscatter signal, and variance) to exactly one of the $k$ clusters defined by centroids (cluster centers), where $k$ is chosen before the algorithm starts (Anderberg, 1973; Toledo et al., 2014). The algorithm works as follows:

- Step 1. Choose $k$ initial cluster centers (centroid).

- Step 2. Compute point-to-cluster-centroid Euclidean distances of all observations.

- Step 3. Assign each observation to the cluster with the closest centroid.

- Step 4. Compute the average of the observations in each cluster to obtain new centroid locations.

- Step 5. Repeat steps 2 through 4 until cluster assignments do not change, or the maximum number of iter-

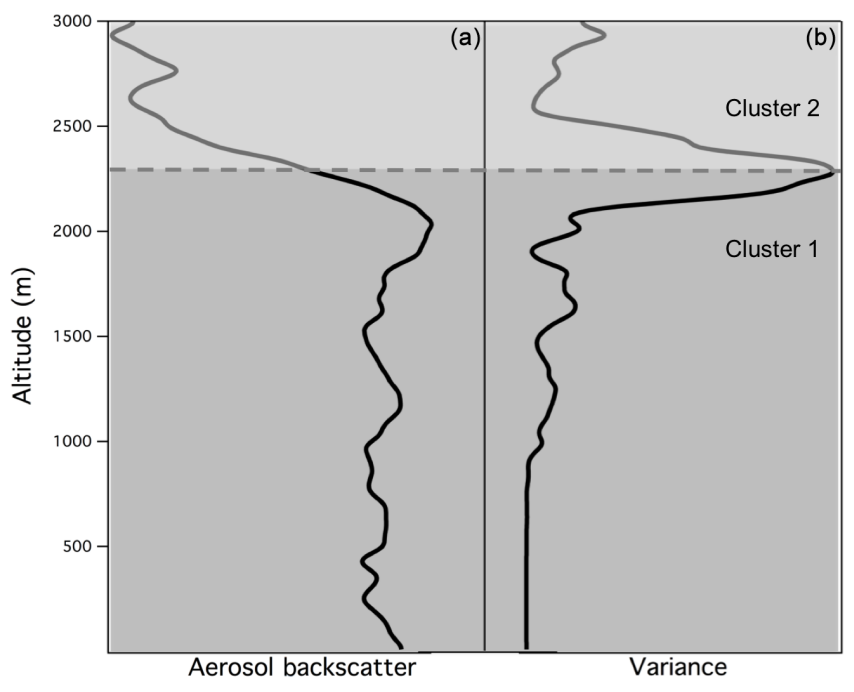

Figure 4. CL31 aerosol backscatter profile (a) and corresponding calculated variance profile (b) for 25 September 2014 at 14:30 CST. Dashed line shows the cluster-derived BLH $(2360 \mathrm{~m})$ at the height where the variance cluster assignment changes from cluster 1 to cluster 2 .

ations is reached, whichever occurs first, depending on computational resources (Toledo et al., 2014).

Previous determination of the number of clusters present or needed in the data set is required for cluster validation, since the number of clusters is a parameter to be introduced into the cluster algorithm (Step 1).

By choosing $k=2$, cluster analysis will typically divide a well-mixed boundary layer into two clusters, one below a peak in variance corresponding to the center of the EZ and one above the variance peak (Fig. 4); however, profiles with increasing noise and/or lofted aerosol layers will cause the cluster analysis to assign clusters elsewhere (for a detailed description see Sect. 4). The maximum height of these clusters is limited by the time of day to prevent the detection of other aerosol layers such as the top of the residual layer during nocturnal hours when only the NSL is of interest. Here, the maximum height for nighttime BL detection is $400 \mathrm{~m}$, whereas it is $2800 \mathrm{~m}$ for daytime BL heights.

\subsection{Haar wavelet method}

Aerosol backscatter BLHs are derived with a covariance wavelet transform utilizing the Haar wavelet compound step function with multiple user-defined wavelet dilations (Cohn and Angevine, 2000; Davis et al., 2000; Brooks, 2003; Baars et al., 2008; Compton et al., 2013; Uzan et al., 2016). This method identifies the sharp aerosol backscatter gradient corresponding to the top of the $\mathrm{BL}$ by calculating the wavelet 


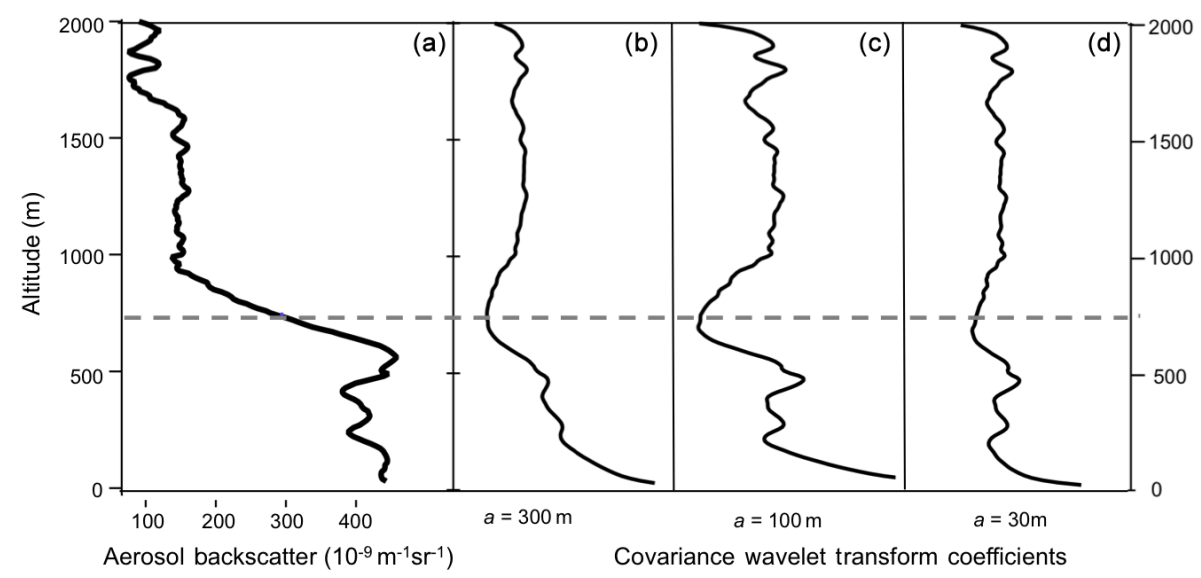

Figure 5. Daytime aerosol backscatter profile (a) for 13 November 2013 at 13:30 CST and (b-c) its corresponding covariance wavelet transform coefficients with increasing magnitudes of 30,100 , and $300 \mathrm{~m}$, respectively. Wavelet-retrieved BLH is shown as the dashed grey line at $750 \mathrm{~m}$.

transform. The Haar wavelet function $h$ is defined as follows:

$h\left(\frac{z-b}{a}\right)=\left\{\begin{array}{ll}-1: & b-\frac{a}{2} \leq z<b \\ +1: & b \leq z \leq b+\frac{a}{2} \\ 0: & \text { elsewhere }\end{array}\right\}$,

where $z$ is the vertical altitude in this application, $a$ is the vertical extent or dilation of the Haar function, and $b$ is the center of the Haar wavelet function. The covariance transform of the Haar wavelet function, $w_{\mathrm{f}}$, is defined as

$w_{\mathrm{f}}(a, b)=a^{-1} \int_{z_{\mathrm{b}}}^{z_{\mathrm{t}}} f(z) h\left(\frac{z-b}{a}\right) \mathrm{d} z$,

where $z_{\mathrm{t}}$ and $z_{\mathrm{b}}$ are the top and bottom altitudes in the aerosol backscatter profile, $f(z)$ is the aerosol backscatter profile as a function of altitude, and $a$ is the normalization factor or the inverse of the dilation.

Defining the dilation factor $a$ and the range of centers $b$ of the Haar wavelet function is key in correctly identifying the BLH using aerosol backscatter profiles. In this study, $b$ ranges from the lowest ceilometer-recorded aerosol backscatter altitude of $10 \mathrm{~m}$ to a maximum BLH of $2800 \mathrm{~m}$. This limit was set as no previous studies have found BLHs above $2800 \mathrm{~m}$ for the study area (Haman et al., 2012; Rappenglück et al., 2008).

As with previous studies (Brooks, 2003; Baars et al., 2008; Compton et al., 2013; Scarino et al., 2014), the dilation factor $a$ affects the number of covariance wavelet transform coefficient (CWTC) local minimums. Larger values create a few large local minimums (Fig. 5b and c) at the heights of the biggest aerosol gradients in the aerosol backscatter profile (Fig. 5a). Lower dilation values also create numerous CWTC local minimums (Fig. 5d) at heights of smaller aerosol gradients in the measured profiles. A range of dilation values is applied to the aerosol backscatter profile. Here we use a maximum dilation of $30 \mathrm{~m}$ for nighttime BLHs since the NSL tends to have a smaller aerosol backscatter gradient than the above RL, creating a need for more than one local minimum (not shown). In these cases, the CWTC local minimum closest to the surface is chosen as the BL. A higher limit of $300 \mathrm{~m}$ (Fig. 5b) for the dilation factor $a$ is applied for daytime BLHs and the strongest CWTC local minimum is used to identify the sharp transition between ML and FT. This larger dilation value also serves to decrease signals from smaller aerosol gradients below the BLH. Cloud-free CL31 aerosol backscatter profiles are averaged first vertically according to Table 1 followed by a $10 \mathrm{~min}$ average before applying the Haar wavelet algorithm. The algorithm is applied to each averaged profile with incremental dilations until the maximum dilation factor is reached ( $30 \mathrm{~m}$ for nighttime hours and $300 \mathrm{~m}$ for daytime hours). The mean of all resulting CWT coefficients is then calculated, and the local minimum of the mean CWT coefficients is identified as the BLH.

\section{Results}

BLH retrieval methods are evaluated and quantified against radiosonde-derived BLHs using bias and standard deviation calculated in accordance with Nielsen-Gammon et al. (2008) and Haman et al. (2012). Here, the bias is the difference between the means of aerosol-retrieved BLH and the corresponding radiosonde $\mathrm{BLH}$, and the standard deviation is the root-mean-square value of the departures of the individual pair sample differences from the bias. A two-sided, pairedsample $t$ test is used to define the statistical significance of the bias:

$t=\frac{\bar{X}-\mu}{S} \sqrt{N}$, 


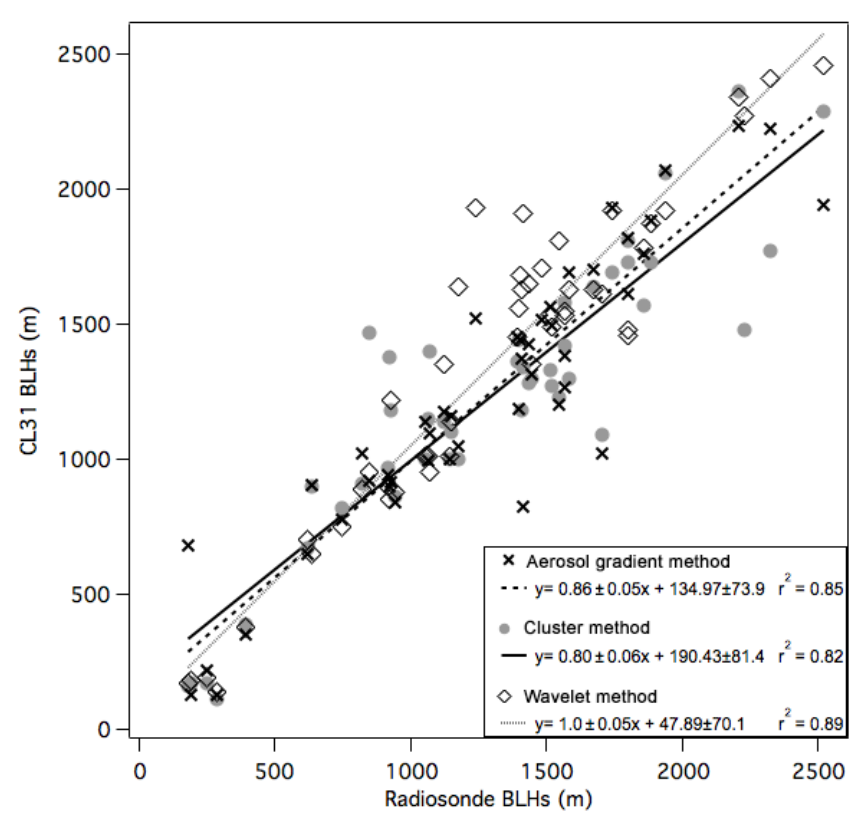

Figure 6. Comparison of CL31 aerosol backscatter BLHs and radiosonde-derived BLHs. The three methods tested are compared to radiosonde BLHs calculated using the skew-T-log-P method. The linear regression lines, regression line equations, and correlation coefficients $r^{2}$ are listed for each BLH retrieval method comparison.

where $\bar{X}$ is the mean of the aerosol BLH samples, $\mu$ is the radiosonde BLHs mean, $S$ is the standard deviation of samples differences, and $N$ is the number of pair samples.

The null hypothesis is defined as unbiased aerosol-derived BLHs when compared to radiosonde BLHs. It was not rejected when the calculated $t$ test value $(t)$ was within \pm 1.96 and the $p$ value was greater than 0.05 or $5 \%$ significance level, in alignment with previous approaches (NielsenGammon et al., 2008; Haman et al., 2012). Correlation of all methods and radiosonde BLHs is shown in Fig. 6, and a cross-comparison of the methods is found in Fig. 7. The uncertainties from the sensor were not calculated for this study as the exact aerosol backscatter profiles used in the aerosol gradient method are not given by the Vaisala algorithm and therefore the uncertainties could not be calculated equally across all BLH retrieval methods. However, Biavati et al. (2015) show a promising new statistical method to review sensor-related uncertainties in similar studies.

The algorithms were applied to 24 October 2013, when two radiosondes were launched in cloud-free conditions. The cluster analysis and wavelet method were subjected to a $500 \mathrm{~m}$ height detection limit during nighttime BLH detection in order to prevent the detection of RL signals and $2800 \mathrm{~m} 2 \mathrm{~h}$ after sunrise at 09:30 CST (the afternoon decoupling period is not considered). The $500 \mathrm{~m}$ and $2800 \mathrm{~m}$ limits are chosen as they are well above the previously identified BLHs in the study area (Haman et al., 2012; Rappenglück et al., 2008). The results are shown in Fig. 8 and discussed in Sect. 4.1.

\subsection{Aerosol backscatter gradient method results}

A previous study done by Haman et al. (2012) found that ceilometer BLHs derived from the aerosol backscatter gradient showed excellent correlation with radiosonde BLHs for both stable and unstable conditions, over a period of 2 years using more than 60 daytime radiosonde profiles. Haman et al. (2012) found the aerosol backscatter gradient capable of continuously identifying the height of the BL after manually choosing one of the three resulting aerosol layers, with limited detection following precipitation or during periods of high wind speeds. Low aerosol content after rain events through wet deposition of aerosols and dispersion of aerosol due to high winds speeds limit the formation of aerosol layers, therefore limiting the detection of the BLH with aerosol gradients. These limitations, however, are less relevant for air quality studies since typically these situations are also accompanied by lower pollutant levels (e.g., through air mass change, enhanced vertical mixing, enhanced dry deposition due to high winds, and wet removal of soluble gases during the preceding precipitation). Late-afternoon hours also present a challenge since the discontinuous transition from unstable (ML) to stable boundary layer (NSL) can create multiple aerosol layers (Endlich et al., 1979; Seibert et al., 2000; Haman et al., 2012). This is still an important time period for primary pollutant concentrations as they would still be critically determined by the BLH (in particular during evening rush hour); however the diurnal peak in photochemistry activity for buildup of secondary pollutants has passed, making this a less crucial time for these pollutants.

This study found similar results using 47 cloud-free radiosondes with a slight difference in correlation most likely due to the manual analysis used. Haman et al. (2012) does not report a BLH if the height of the BL is not clear, while this study always reports a gradient found by the algorithm as long as the algorithm is able to calculate a gradient. The manual analysis used in this study resulted in a correlation coefficient $\left(r^{2}\right)$ of 0.85 (Fig. 6) when comparing the aerosol backscatter gradient BLHs to daytime radiosonde BLHs. A bias of $-42.5 \mathrm{~m}$, and a standard deviation of $209.5 \mathrm{~m}$ (Table 2) were found (not statistically significant; $p>0.05$ ). The bias indicates aerosol gradient method BLHs are generally lower than radiosonde BLHs. The overall agreement shows the ability of this method to calculate the BLH reasonably well once one of the three calculated aerosol backscatter gradients is chosen as the BL. However, this requires a priori knowledge of typical BLHs at the measurement site and a manual inspection of aerosol gradients calculated. In addition, limited detection of the BLH was also seen in conditions with low aerosol content when the algorithm did not find strong enough gradients in the aerosol backscatter profile. No combination of available setting options was found to improve BLH detection in these conditions. Furthermore, disagreement was found when the largest gradient in an aerosol profile does not correspond to the thermodynamic 

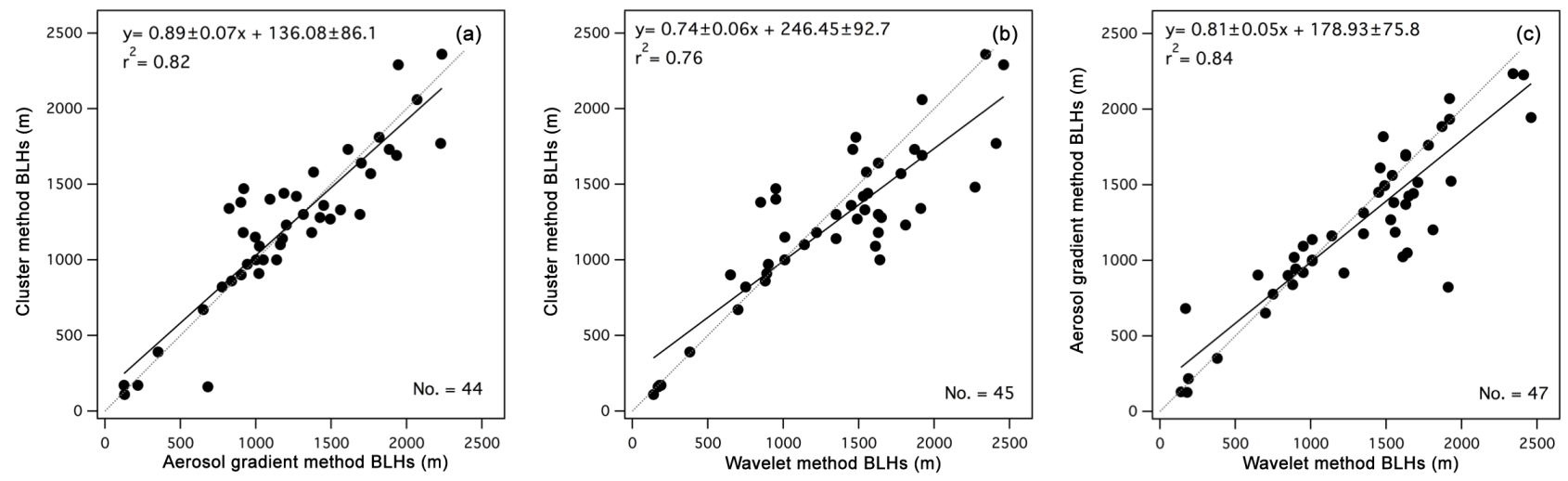

Figure 7. Intercomparison of all methods using cloud-free profiles. One-to-one line in dashed grey and linear regression lines in solid black.

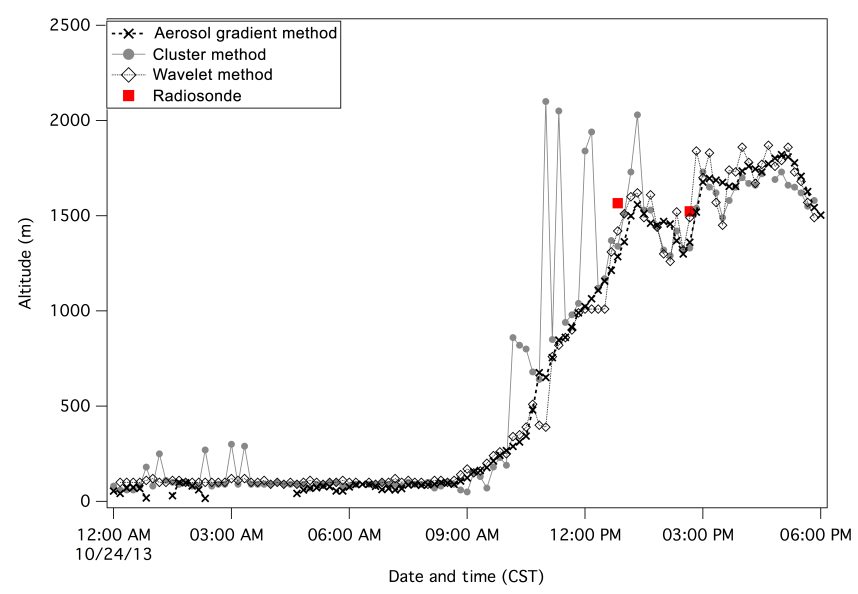

Figure 8. Resulting BLH for 24 October 2013 with 10 min averages for all methods. Radiosonde-estimated BLHs are shown as red squares.

$\mathrm{BLH}$ found using radiosonde profiles. This is due to the different assumptions in the methodologies when using aerosol gradients to detect lidar BLHs or thermal parameters to detect radiosonde BLHs.

Figure 8 shows a time series of BLHs reported after manual analysis of radiosonde BLHs and 10 min averaging of the three calculated aerosol layers (Fig. 3). The gradient method is able to resolve for BLHs under stable and unstable conditions for this October day but underestimates the BLH by about 300 and $170 \mathrm{~m}$ when compared to the first and second radiosonde launch, respectively. Nocturnal BLHs are similar to those calculated by the wavelet and cluster analysis method but occasionally measure a lower NSL than the other two methods, likely due to the difference with the averaging procedure used for the aerosol gradient method. Daytime BLHs after manual selection of the three calculated gradients are seen as slightly less variable than those calculated by the cluster analysis and wavelet methods and are occasionally lower than those calculated by the wavelet method.
Overall, all methods are able to capture the NSL, the growth of the BL, and the peak BLH reasonably well, with the cluster method showing the most variability due to the detection of lofted aerosol layer signals incorrectly identified as the BLH. The aerosol gradient method and the wavelet method BLHs show very similar results after the manual selection of the aerosol gradient method BLHs and are also found to be within the standard deviation of the climatological mean for the fall season found by Haman et al. (2012) for this site. Figure 7 shows the aerosol gradient method having the best correlation with the wavelet method, as expected, as both search for the maximum aerosol backscatter gradients in a profile, but slightly lower agreement with the variance method. Overall, this method works well under stable and unstable conditions as long as the user is able to identify the correct BLH from the three gradients reported.

\subsection{Cluster method results}

CL31 BLHs using the cluster method showed a slightly lower correlation than the aerosol gradient method with a correlation coefficient of 0.82 (Fig. 6), a bias of $-61.0 \mathrm{~m}$ and a standard deviation of $243.5 \mathrm{~m}$ (not statistically significant; see Table 2). Disagreements found between radiosonde- and cluster-derived BLHs were most commonly due to noise in aerosol backscatter profiles and lofted aerosol layers. From the 45 comparisons performed, six cases (13.3\%) showed the algorithm finding a single clear peak in variance not corresponding to the BL but to noise (1 case) or to other aerosol layers (5 cases). Sixteen cases $(35.5 \%)$ were found where noise created multiple variance peaks at higher altitudes; therefore the cluster analysis divided aerosol backscatter profiles into clusters of similar variance intensity (Fig. 9) rather than above and below a single variance peak (as seen in Fig. 4). This division underestimated the BLH (bias of -61.0) since the cluster was divided into relatively low variance closer to the surface and high variance at higher altitudes. This is due to the fact that CL31 displays a significant increase in noise with increasing altitude. For the 
Table 2. Bias, standard deviation, $p$ value, and number of data points (no.) for comparison of BLH retrieval methods to radiosonde BLHs.

\begin{tabular}{lrrrr}
\hline BLH retrieval method & Bias $(\mathrm{m})$ & Standard deviation $(\mathrm{m})$ & $p$ value & No. \\
\hline Aerosol gradient & -42.5 & 209.5 & 0.17 & 47 \\
Cluster & -61.0 & 243.5 & 0.10 & 45 \\
Wavelet & 51.1 & 187.0 & 0.07 & 48 \\
\hline
\end{tabular}

five instances where the variance maximum did not equal radiosonde-derived BLH due to signals from lofted aerosol layers, a smaller maximum corresponded to the BL. These errors were not due to the algorithm limitations created by noise $(35.5 \%)$ but instead due to the implicit assumptions in using aerosol backscatter for BLH detection (constant aerosol backscatter signals within the BL and a negative gradient in aerosol backscatter corresponds to the top of the $\mathrm{BL})$. When compared to the wavelet and aerosol gradient method, the cluster analysis agrees well with the aerosol gradient method $\left(r^{2}=0.82\right)$ but slightly less with the wavelet method $\left(r^{2}=0.76\right)$ as seen in Fig. 7 .

The errors caused by other aerosol layers can be seen to occur during 24 October 2013 (Fig. 8). Here, the cluster method mistakenly identifies signals higher than the BL, some of which the aerosol gradient method also identified (see Fig. 3) but were manually rejected as possible BLH candidates. When compared to the radiosondes launched in this day, the cluster analysis agrees well, slightly underestimating the BLH by no more than $100 \mathrm{~m}$ in the first launch and $250 \mathrm{~m}$ in the second launch. The cluster analysis method agrees well during the nocturnal hours, when the algorithm is limited by height, preventing the detection of the RL, but errors occur when the nighttime signals are assigned to clusters caused by noise, similar to the situation shown in Fig. 9b.

\subsection{Wavelet method results}

The Haar wavelet method showed excellent agreement when compared to 48 radiosonde BLHs, with a correlation coefficient of 0.89 (Fig. 6). Statistical analysis showed a bias of $51.1 \mathrm{~m}$ (not statistically significant) and a standard deviation of $187.0 \mathrm{~m}$ (Table 2). Disagreement was found when aerosol backscatter profiles contained multiple sharp gradients corresponding to lofted aerosol layers $(\sim 12.5 \%$ of total cases). These shallow aerosol layers often have stronger gradients than that of the BL. In these cases, the secondlargest gradient is very often the BL $(\sim 67 \%)$. In addition, another $\sim 10 \%$ of total cases showed deviations where the radiosonde-derived $\mathrm{BLH}$ did not correspond to the greatest gradient in the aerosol profile as shown in Fig. 10. This disagreement and positive bias found can be attributed to the differences in determining BLHs using aerosols and thermodynamically using radiosondes. Aerosols can penetrate into the stable layer, transporting aerosols to higher altitudes than the BLH (inversion height) and causing an overestimation

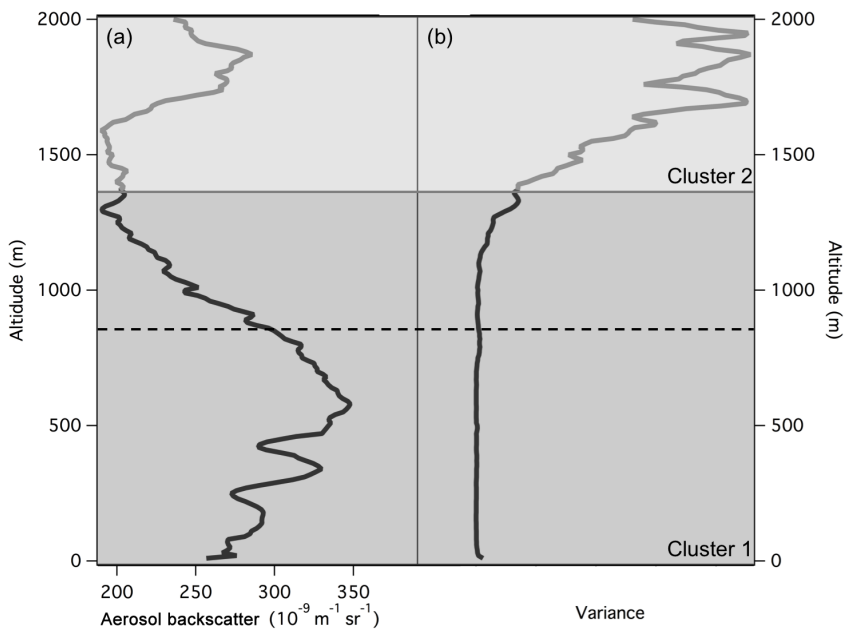

Figure 9. Aerosol backscatter profile (a) on 19 October 2013 at 14:00 CST and corresponding calculated variance profile (b) showing division of cluster analysis and estimated BLH $(1370 \mathrm{~m})$ at the transition from low to high variance. Radiosonde BLH is shown as a dashed line at $850 \mathrm{~m}$.

of aerosol-derived BLHs (McElroy and Smith, 1991; Seibert et al., 2000). Removing the $\sim 22.5 \%$ of deviations falling into the cases described above would improve the correlation drastically $\left(r^{2}=0.98\right)$. This provides confidence that all potential causes of deviations were identified. Overall, the wavelet method showed the best correlation of all methods when compared to radiosondes. In particular, this method was superior in the detection of BLHs in profiles with low aerosol backscatter. Under these conditions it was able to resolve weaker local maximums, thus reasonably capturing the BLH. This method was also less affected by noise than the gradient method or the cluster method.

The wavelet method is shown to perform well with the addition of a height restraint for nocturnal BLH retrievals (Fig. 8) in order to prevent the detection of RL signals or lofted aerosol layers. Other methods to prevent the incorrect detection of the BLH include those proposed by de Haij et al. (2006), Di Giuseppe et al. (2012), and Pal et al. (2013). However, our study uses the height restraint as it has been shown to successfully prevent the detection of RL signals in the example shown in Fig. 8. Both wavelet-estimated BLHs are within $30 \mathrm{~m}$ of the radiosonde-derived BLHs. The comparison with the cluster and gradient methods in Fig. 7 shows that this method generally agrees well with the aerosol gradient 


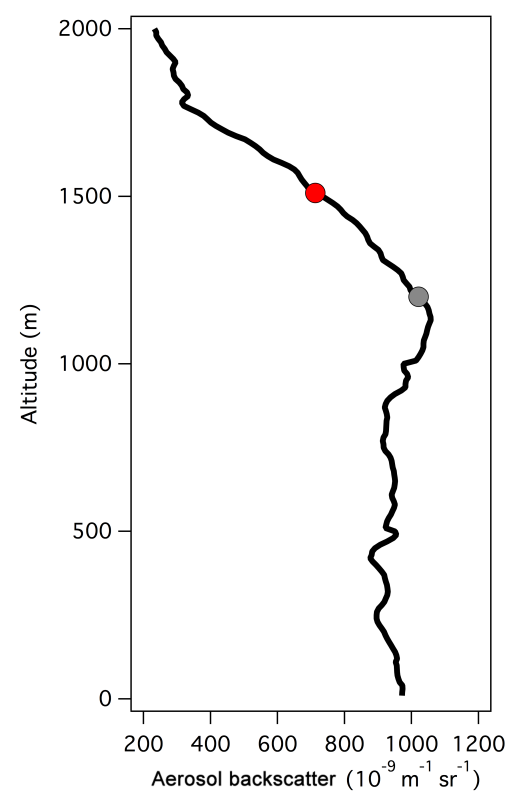

Figure 10. Aerosol backscatter profile for 20 October 2014 at 14:00 CST where radiosonde-derived BLH does not correspond to the height of the largest negative gradient in the aerosol backscatter profile. Radiosonde BLH at $1290 \mathrm{~m}$ is shown as a grey circle, and wavelet-method-derived BLH at $1510 \mathrm{~m}$ is shown as a red circle.

method $\left(r^{2}=0.84\right)$ but appears to calculate the BLH slightly higher, most likely due to differences in the averaging procedures used. The correlation with the variance method of $r^{2}=0.76$ is most likely due to the noise sensitivity of the cluster analysis method and the calculation of a BLH by using the variance of an aerosol backscatter profile versus finding a gradient in an aerosol backscatter profile.

\subsection{BLH retrieval with cloud signals}

The identification of the BLH is more difficult in the presence of clouds when aerosol backscatter algorithms identify the strong signals of the cloud layer as the BLH. Strong cloud signals $\left(>2000 \times 10^{-9} \mathrm{~m}^{-1} \mathrm{sr}^{-1}\right)$ can limit the detection of the BLH due to the extinction of the aerosol backscatter signals above cloud layers. The effect of these cloud signals is observed for all BLH retrieval methods presented here (fog or rain events were not analyzed). Although this study observes daytime cloud signals, continuous ceilometer measurements may find similar signals during nighttime hours; therefore our findings are not limited to daytime convective mixed layers.

Figure 11 shows hourly aerosol backscatter profiles for 15 September 2013 and corresponding BLHs retrieved by the aerosol gradient, cluster, and wavelet methods. Both aerosol gradient and wavelet methods consistently identify the BLH as the top of the cloud layer due to the large negative gradient created by strong cloud signals. This is often the height of the thermodynamic BL identified using relative humidity

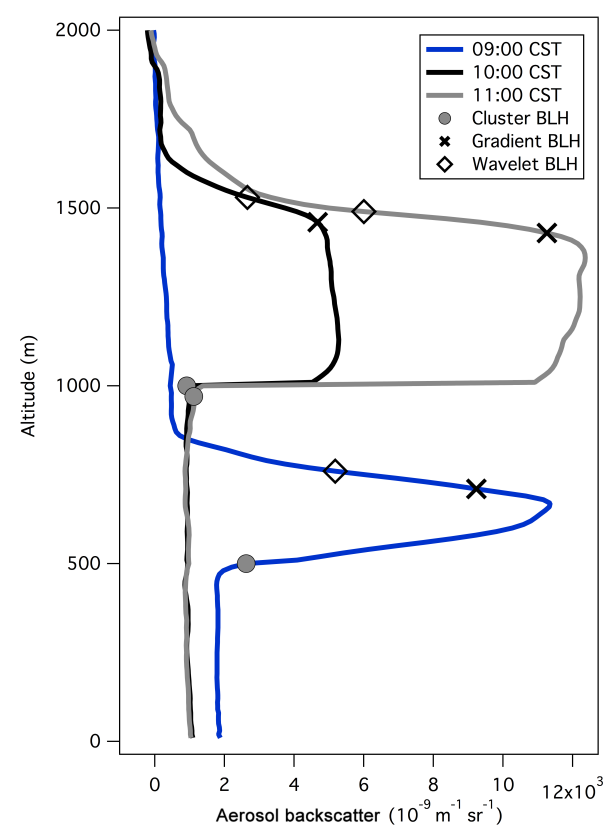

Figure 11. Aerosol backscatter profiles on 15 September 2013 measured at 09:00 CST (blue), 10:00 CST (black), and 11:00 CST (grey). BLHs retrieved by each method are shown on all profiles. Cloud layer signals measured at about 470-870, 1000-1620, and 1000-1520 m for 09:00, 10:00, and 11:00 CST, respectively.

and dew point temperature methods, which find the height of the ML as the sharp decrease in moisture at the top of the cloud layer. Low cloud layers, however, impede the detection of the above BLH; therefore the aerosol gradient and wavelet method will mistakenly identify the large gradient of the low cloud layers as the BLH, while the cluster method will identify the BL as the base of the low cloud layer. The aerosol gradient method typically found the BLH at the beginning of the large negative gradient (top of the cloud layer), while the wavelet method calculated the BLH slightly higher than the aerosol gradient method. Differences between these two methods were found to not exceed $200 \mathrm{~m}$ and could be attributed to the different averaging settings applied for these methods.

The cluster method was found to constantly identify the cloud base as the BLH by assigning aerosol signals into a cluster of cloud signals and a second cluster of cloud-free signals with the first transition (BLH) of these clusters located at the base of the cloud layer, for example, at $970 \mathrm{~m}$ for the example shown in Fig. 12. A second transition of clusters is located at the top of the cloud layer (about $1400 \mathrm{~m}$ ) corresponding to the BLHs retrieved by the aerosol gradient and wavelet methods. The cluster method then essentially calculates the cloud layer depth by assigning a cluster solely to the cloud layer.

The effect of clouds in the overall correlation between aerosol backscatter methods and radiosonde BLHs in both cloud and cloud-free profiles is seen in Fig. 13. During a fully 


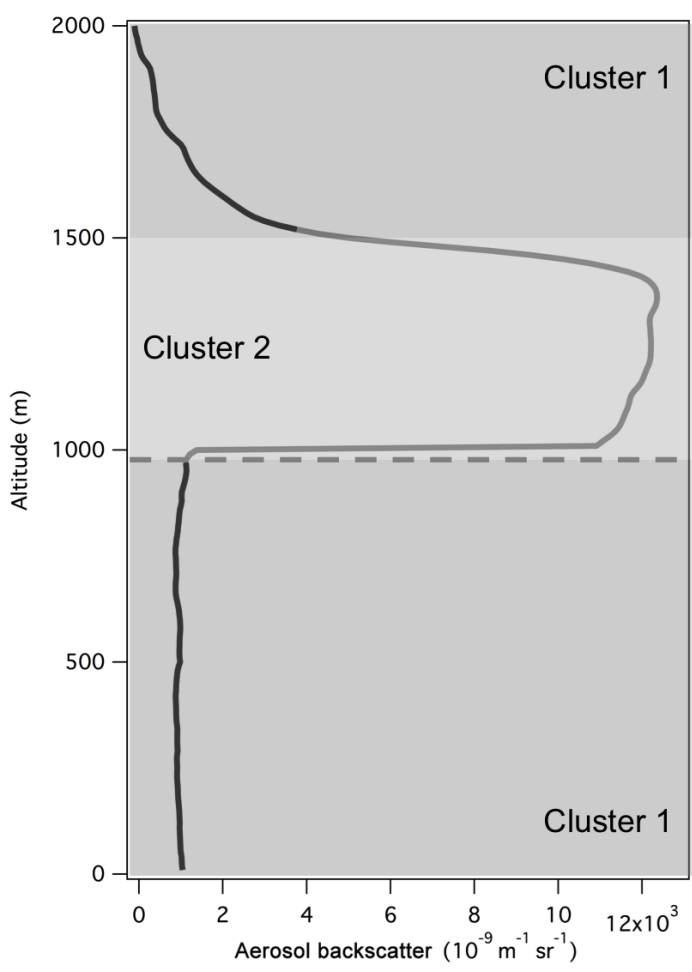

Figure 12. Cluster assignments of aerosol backscatter profile with cloud layer at about 1000-1520 m on 15 September 2013 measured at 11:00 CST. Automated BLH was found at $970 \mathrm{~m}$.

developed convective cloud-topped ML, the aerosol gradient methods agree reasonably well with the radiosonde-derived BLHs. However, under less developed MLs the agreement decreases due to the aerosol gradient methods identifying the BLH at the top of a cloud layer, while the skew-T-log$\mathrm{P}$ method finds the BL at a strong inversion lower than the cloud layer. This effect can be seen in the radiosonde BLH range of about 800 to $1500 \mathrm{~m}$ in Fig. 13. The cluster analysis method showed the highest decrease in correlation with regard to the cloud-free analysis presented in Fig. 6 due to the detection of the cloud base.

The presence of clouds creates difficulties in the detection of the BLH for all methods due to the extinction of aerosol backscatter signals above the cloud, the presence of low clouds mistakenly identified as the BLH, or the detection of high cloud signals above the skew-T-log-P-derived $\mathrm{BLH}$. Hence the removal of profiles with cloud signals is preferred for the automatic retrieval of the BLH. This affects the cluster and aerosol gradient methods in particular since the moving time averaging performed before the application of the algorithms will expand cloud signals to a greater number of profiles, subsequently eliminating these profiles for BLH detection.

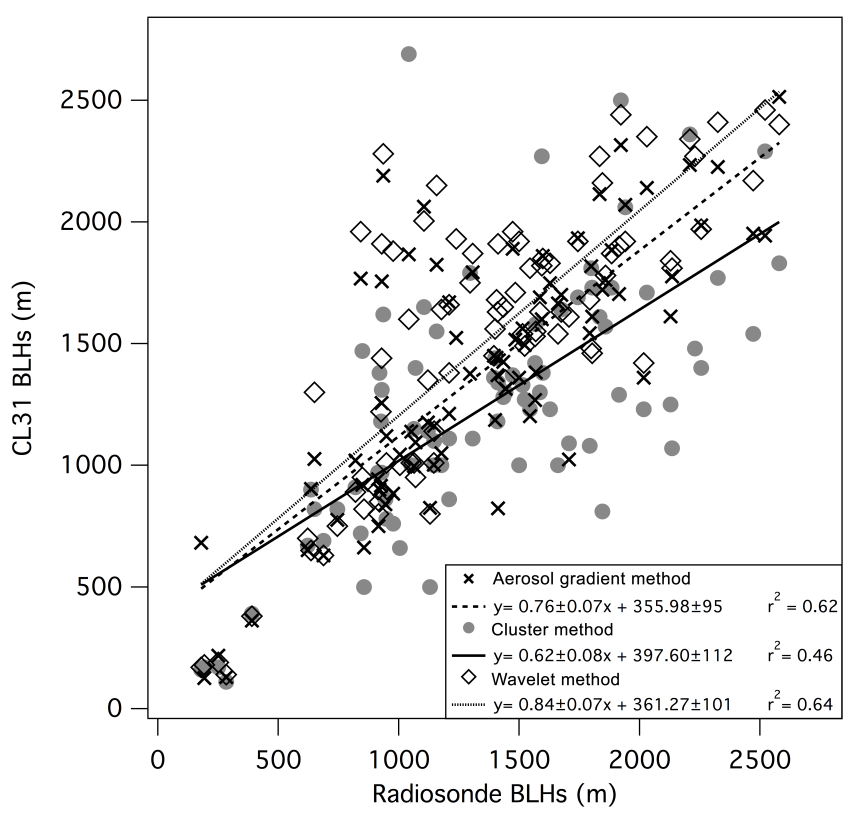

Figure 13. Comparison of CL31 aerosol backscatter BLHs and radiosonde-derived BLHs including cloud signals. The linear regression lines, regression line equations, and correlation coefficients $r^{2}$ are listed for each BLH retrieval method comparison.

\section{Summary and conclusions}

Aerosol-backscatter-derived boundary layer heights from three distinct methods were tested and compared to radiosonde-retrieved BLHs. An aerosol gradient method, a cluster analysis method, and a Haar wavelet method were compared to daytime radiosonde profiles using measured aerosol backscatter from a Vaisala CL31 ceilometer. This comparison used 47 radiosondes for the aerosol gradient method, 45 for the cluster analysis method, and 48 for the Haar wavelet method due to limitations implicit to each algorithm (see Sect. 4). The first method, the Vaisala Corp. aerosol gradient method, finds the three largest gradients in an aerosol backscatter profile, one of which must be chosen as the height of the boundary layer. The second method, a cluster analysis method, calculates variance in an aerosol backscatter profile with the BLH correlating to a peak in variance. $K$-means cluster analysis then divides a variance profile at the height of the BL (variance peak). The final method uses a covariance wavelet transform utilizing the Haar wavelet compound step function to identify a sharp aerosol backscatter gradient corresponding to the top of the BL by calculating the wavelet transform at various dilations. The results presented here used daytime measurements only; however the findings can be applied to similar signals to those found in the nighttime residual and nocturnal stable layers.

Overall good agreement was found for all methods, with no statistically significant bias found. Yet all methods found 
cases where thermodynamic BLHs from radiosondes did not correlate with a maximum gradient in aerosol backscatter due to differences in thermodynamic and aerosol BLHs and the methodology used to derive these heights. The comparison between the aerosol gradient method and radiosondederived BLHs showed difficulties in determining the BLH in low-aerosol-backscatter conditions. The calculation of the three largest gradients particular to this method was useful in situations where the largest gradient does not correlate with the radiosonde-derived BLH. Yet this requires a priori knowledge of typical boundary layer heights and evolution in the location of interest. In contrast, the cluster method showed drawbacks due to sensitivity to noise-generated artifacts or lofted aerosol layers where the algorithm mistakenly found peaks in variance and incorrectly identified them as the BLH. Profiles were also mistakenly divided due to the increasing noise with height rather than a peak in variance, underestimating the height of the BL. With this automated cluster analysis method, previous knowledge of the BL aids in identifying such algorithm errors but is otherwise not necessary. Further work is needed to improve the cluster method sensitivity to noise and should be kept in mind when using the cluster method or other variance-based algorithms for BLH detection. All methods are able to resolve for BLHs under stable and unstable conditions after manual selection of the calculated aerosol backscatter gradients reported by the aerosol gradient method and an addition of a height limit of $500 \mathrm{~m}$ for nighttime hours applied to both the wavelet and cluster methods. The cluster method showed the most variability due to the incorrect identification of lofted aerosol layer signals as the BLH, while the aerosol gradient method and the wavelet method BLHs showed very similar results for the tested time period.

Overall, the wavelet method showed the best agreement of all methods tested here, with $77.5 \%$ of cases showing excellent agreement with radiosonde BLHs without previous knowledge of the BL required, as this method is also automated. The cases where deviations occurred $(\sim 22.5 \%$ of all observations) were due to multiple sharp gradients corresponding to lofted aerosol layers and to the thermodynamically derived BLH not corresponding to the greatest gradient in an aerosol profile (Fig. 10). A bias of $51.1 \mathrm{~m}$ was found, indicating that wavelet method BLHs are generally higher than radiosonde-derived BLHs. This disparity has been previously attributed to aerosol penetrating into the stable layer above the BLH, leading to the overestimation of aerosol-derived BLHs (McElroy and Smith, 1991; Seibert et al., 2000). The wavelet method also showed a higher ability to calculate the BLH under low-aerosol conditions.

The effect of cloud signals in the determination of the BLH showed a clear difference between the negative-gradient methods (aerosol backscatter and wavelet methods) and the cluster analysis method. Both aerosol gradient and wavelet methods identify the BLH as the top of the cloud layer where a sharp negative gradient created by strong cloud signals was found, while the cluster method identified the BLH as the base of the cloud layer. The cluster method was found to assign a cluster for cloud signal and a cluster for cloud-free signal along an aerosol backscatter profile (Fig. 12). The automatic detection of the first transition of clusters identifies the BLH as the base of the cloud layer with the second transition at the top of the cloud layer; i.e., it identifies the cloud layer depth. Limited detection of the BLH in aerosol profiles with cloud signals is seen for all methods (Fig. 13), with the cluster and aerosol gradient methods being more sensitive due to the moving time averaging applied, expanding cloud signals to a greater number of profiles and consequently eliminating these profiles for BLH detection. Both the wavelet and aerosol gradient methods agree reasonably well with the radiosonde-derived BLHs in a fully developed convective cloud-topped ML. Agreement decreases when the aerosol gradient and wavelet methods identify the BLH at the top of a cloud layer, while the skew-T-log-P BLHs are calculated at a height lower than the cloud layer under less developed MLs.

The results presented here demonstrate the ability of the Haar wavelet method to more accurately detect BLHs than the aerosol gradient and cluster methods while requiring the least amount of manual inspection. The errors found with this method were due to lofted aerosol layers, low-level clouds, and differences in determining BLHs using aerosols and thermodynamically using radiosondes. In order to use this method on other instruments and locations, dilation values should be determined carefully and individually. Out of the three methods tested in this study, it is suggested to employ the wavelet method in future studies, in particular for longterm seasonal and diurnal boundary layer studies and spatial analysis of the BL using multiple lidar aerosol backscatter measurements. A combination of the wavelet method BLH retrievals during clear skies and the cluster analysis method's ability to calculate cloud depth is also recommended for more robust BL studies to retrieve more information about the boundary layer under both conditions, as both the wavelet and cluster analysis methods were seen to perform well using various lidar instruments in studies such as Compton et al. (2013), Scarino et al. (2014), and Toledo et al. (2014). Although not tested in this study, recent work by de Bruine et al. (2016) and Poltera et al. (2017) show promising results using an automated method which reduces incorrect detection of the BLH using graph theory.

Data availability. Data used in this study are available from the authors upon request.

Competing interests. The authors declare that they have no conflict of interest. 
Acknowledgements. We wish to thank Christoph Münkel for all assistance provided with the ceilometer and Vaisala BL Matlab algorithm, and James Flynn and Sergio Alvarez for assistance in the installation and maintenance of the ceilometer. Part of this work was funded by the Texas Commission of Environmental Quality (TCEQ) and the NASA DISCOVER-AQ project.

Edited by: D. Ruffieux

Reviewed by: two anonymous referees

\section{References}

Anderberg, M. R.: Cluster Analysis for Applications, Academic Press, 1973.

André , J. C. and Mahrt, L.: The Nocturnal Surface Inversion and Influence of Clear-Air Radiative Cooling, J. Atmos. Sci., 39, 864878, 1982.

Baars, H., Ansmann, A., Engelmann, R., and Althausen, D.: Continuous monitoring of the boundary-layer top with lidar, Atmos. Chem. Phys., 8, 7281-7296, doi:10.5194/acp-8-7281-2008, 2008.

Berman, S., Ku, J. Y., and Rao, S. T.: Spatial and temporal variation in the mixing depth over the northeastern United States during the summer of 1995, J. Appl. Meteor., 38, 1661-1673, 1999.

Biavati, G., Feist, D. G., Gerbig, C., and Kretschmer, R.: Error estimation for localized signal properties: application to atmospheric mixing height retrievals, Atmos. Meas. Tech., 8, 42154230, doi:10.5194/amt-8-4215-2015, 2015.

Brooks, I. M.: Finding Boundary Layer Top: Application of a Wavelet Covariance Transform to Lidar Backscatter Profiles, J. Atmos. Ocean. Tech., 20, 1092-1105, 2003.

Cohn, S. and Angevine, W.: Boundary layer height and entrainment zone thickness measured by lidars and wind-profiling radars, J. Appl. Meteor., 39, 1233-1247, 2000.

Compton, J. C., Delgado, R., Berkoff, T. A., and Hoff, R. M.: Determination of Planetary Boundary Layer Height on Short Spatial and Temporal Scales: A Demonstration of the Covariance Wavelet Transform in Ground-Based Wind Profiler and Lidar Measurements, J. Atmos. Ocean. Tech., 30, 1566-1575, doi:10.1175/JTECH-D-12-00116.1, 2013.

Davis, K. J., Gamage, N., Hagelberg, C. R., Kiemle, C., Lenschow, D. H., and Sullivan, P. P.: An objective method for deriving atmospheric structure from airborne lidar observations, J. Atmos. Ocean. Tech., 17, 1455-1468, 2000.

Day, B. M., Rappenglück, B., Clements, C. B., Tucker, S. C., and Brewer, W. A.: Nocturnal boundary layer characteristics and land breeze development in Houston, Texas, during TexAQS-II, Atmos. Environ., 44, 4014-4023, doi:10.1016/j.atmosenv.2009.01.031, 2010.

de Bruine, M., Apituley, A., Donovan, D., Klein Baltink, H., and de Haij, M.: Pathfinder: Applying graph theory for consistent tracking of daytime mixed layer height with backscatter lidar, Atmos. Meas. Tech. Discuss., doi:10.5194/amt-2016-327, in review, 2016.

de Haij M., Wauben W., and Baltink, H. K.: Determination of mixing layer height from ceilometer backscatter profiles, Proc. SPIE 6362, 63620R-63620R-12, doi:10.1117/12.691050, 2006.
Di Giuseppe, F., Riccio, A., Caporaso, L., Bonafé, G., Gobbi, G. P., and Angelini, F.: Automatic detection of atmospheric boundary layer height using ceilometer backscatter data assisted by a boundary layer model, Q. J. Roy. Meteorol. Soc., 138, 649-663, doi:10.1002/qj.964, 2012.

Emeis, S., Münkel, C., Vogt, S., Müller, W. J., and Schäfer, K.: Atmospheric boundary-layer structure from simultaneous SODAR, RASS, and ceilometer measurements, Atmos. Environ., 38, 273 286, doi:10.1016/j.atmosenv.2003.09.054, 2004.

Emeis, S. and Schäfer, K.: Remote Sensing Methods to Investigate Boundary-layer Structures relevant to Air Pollution in Cities, Bound.-Lay. Meteorol., 121, 377-385, 2006.

Emeis, S., Schäfer, K., and Münkel, C.: Long-term observations of the urban mixing-layer height with ceilometers, IOP Conference Series: Earth and Environ. Sci. 1, 012027, 2008a.

Emeis, S., Schäfer, K., and Münkel, C.: Surface-based remote sensing of the mixing-layer height - a review, Meteorol. Z., 17, 621630, $2008 b$.

Emeis, S., Schäfer, K., Münkel, C., Friedl, R., and Suppan, P.: Evaluation of the Interpretation of Ceilometer Data with RASS and Radiosonde Data, Bound.-Lay. Meteorol., 143, 2535, doi:10.1007/s 10546-011-9604-6, 2012.

Endlich, R., Ludwig, F., and Uthe, E.: An automatic method for determining the mixing depth from lidar observations, Atmos. Environ., 13, 1051-1056, 1979.

Eresmaa, N., Karppinen, A., Joffre, S. M., Räsänen, J., and Talvitie, H.: Mixing height determination by ceilometer, Atmos. Chem. Phys., 6, 1485-1493, doi:10.5194/acp-6-1485-2006, 2006.

Garratt, J. R.: The internal boundary layer - A review, Bound.-Lay. Meteorol., 50, 171-203, doi:10.1007/BF00120524, 1990.

Haeffelin, M., Angelini, F., Morille, Y., Martucci, G., Frey, S., Gobbi, G. P., Lolli, S., O’Dowd, C. D., Sauvage, L., XuerefRémy, I., Wastine, B., and Feist, D. G.: Evaluation of MixingHeight Retrievals from Automatic Profiling Lidars and Ceilometers in View of Future Integrated Networks in Europe, Bound.Lay. Meteorol., 143, 49-75, 2012.

Haman, C. L., Lefer, B., and Morris, G. A.: Seasonal Variability in the Diurnal Evolution of the Boundary Layer in a NearCoastal Urban Environment. J. Atmos. Ocean. Tech., 29, 697710, doi:10.1175/JTECH-D-11-00114.1, 2012.

Haman, C. L., Couzo, E., Flynn, J. H., Vizuete, W., Heffron, B., and Lefer, B. L.: Relationship between boundary layer heights and growth rates with ground-level ozone in Houston, Texas, J. Geophys. Res.-Atmos., 119, 6230-6245, doi:10.1002/2013JD020473, 2014.

Hooper, W. P. and Eloranta, E. W.: Lidar measurements of wind in the planetary boundary layer: The method, accuracy and results from joint measurements from radiosonde and kytoon, J. Appl. Meteorol. Clim., 25, 990-1001, 1986.

Kamp, D. and McKendry, I.: Diurnal and Seasonal Trends in Convective Mixed-Layer Heights Estimated from Two Years of Continuous Ceilometer Observations in Vancouver, BC, Bound.Lay. Meteorol., 137, 459-475, doi:10.1007/s10546-010-9535-7, 2010.

Kotthaus, S., O'Connor, E., Münkel, C., Charlton-Perez, C., Haeffelin, M., Gabey, A. M., and Grimmond, C. S. B.: Recommendations for processing atmospheric attenuated backscatter profiles from Vaisala CL31 ceilometers, Atmos. Meas. Tech., 9, 37693791, doi:10.5194/amt-9-3769-2016, 2016. 
Kovalev, V. A. and Eichinger, W. E.: Elastic Lidar: Theory, Practice and Analysis Methods, Wiley and Sons, 2004.

McElroy, J. L. and Smith, T. B.: Lidar Descriptions of Mixing-Layer Thickness Characteristics in a Complex Terrain/Coastal Environment, J. Appl. Meteorol., 30, 585-597, 1991.

McKendry, I. G., van der Kamp, D., Strawbridge, K. B., Christen, A., and Crawford, B.: Simultaneous observations of boundary-layer aerosol layers with CL31 ceilometer and 1064/532 nm lidar, Atmos. Environ., 43, 5847-5852, doi:10.1016/j.atmosenv.2009.07.063, 2009.

Milroy, C., Martucci, G., Lolli, S., Loaec, S., Sauvage, L., XuerefRemy, I., Lavrič, J. V., Ciais, P., Feist, D. G., Biavati, G., and O'Dowd, C. D.: An Assessment of Pseudo-Operational GroundBased Light Detection and Ranging Sensors to Determine the Boundary-Layer Structure in the Coastal Atmosphere, Adv. Meteor., 2012, 18 pp., doi:10.1155/2012/929080, 2012.

Münkel, C., Eresmaa, N., Räsänen, J., and Karppinen, A.: Retrieval of mixing height and dust concentration with lidar ceilometer, Bound.-Lay. Meteorol., 124, 117-128, doi:10.1007/s10546-0069103-3, 2007.

Muñoz, R. C. and Undurraga, A. A.: Daytime Mixed Layer over the Santiago Basin: Description of Two Years of Observations with a Lidar Ceilometer, J. Appl. Meteorol. Clim., 49, 1728-1741, doi:10.1175/2010JAMC2347.1, 2010.

Nielsen-Gammon, J. W., Powell, C., Mahoney, M., Angevine, W., Senff, C., White, A., Berkowitz, C., Doran, C., and Knupp, K.: Multisensor Estimation of Mixing Heights over a Coastal City, J. Appl. Meteor. Clim., 47, 27-43, doi:10.1175/2007JAMC1503.1, 2008.

Pal, S., Haeffelin, M., and Batchvarova, E.: Exploring a geophysical process-based attribution technique for the determination of the atmospheric boundary layer depth using aerosol lidar and nearsurface meteorological measurements, J. Geophys. Res.-Atmos., 118, 9277-9295, doi:10.1002/jgrd.50710, 2013.

Pandolfi, M., Martucci, G., Querol, X., Alastuey, A., Wilsenack, F., Frey, S., O'Dowd, C. D., and Dall'Osto, M.: Continuous atmospheric boundary layer observations in the coastal urban area of Barcelona during SAPUSS, Atmos. Chem. Phys., 13, 49834996, doi:10.5194/acp-13-4983-2013, 2013.

Petäjä, T., Järvi, L., Kerminen, V.-M., Ding, A. J., Sun, J. N., Nie, W., Kujansuu, J., Virkkula, A., Yang, X., Fu, C. B., Zilitinkevich, S., and Kulmala, M.: Enhanced air pollution via aerosol-boundary layer feedback in China, Sci. Rep., 6, 18998, doi:10.1038/srep18998, 2016.

Peña, A., Gryning, S. E., and Hahmann, A. N.: Observations of the atmospheric boundary layer height under marine upstream flow conditions at a coastal site, J. Geophys. Res.-Atmos., 118, 19241940, doi:10.1002/jgrd.50175, 2013.

Piironen, A. K. and Eloranta, E. W.: Convective boundary layer depths and cloud geometrical properties obtained from volume imaging lidar data, J. Geophys. Res.-Atmos., 100, 569-576, 1995.
Poltera, Y., Martucci, G., Collaud Coen, M., Hervo, M., Emmenegger, L., Henne, S., Brunner, D., and Haefele, A.: PathfinderTURB: an automatic boundary layer algorithm. Development, validation and application to study the impact on in-situ measurements at the Jungfraujoch, Atmos. Chem. Phys. Discuss., doi:10.5194/acp-2016-962, in review, 2017.

Rappenglück, B., Perna, R., Zhong, S., and Morris, G. A.: An analysis of the vertical structure of the atmosphere and the upper-level meteorology and their impact on surface ozone levels in Houston, Texas, J. Geophys. Res.-Atmos., 113, D17315, doi:10.1029/2007JD009745, 2008.

Scarino, A. J., Obland, M. D., Fast, J. D., Burton, S. P., Ferrare, R. A., Hostetler, C. A., Berg, L. K., Lefer, B., Haman, C., Hair, J. W., Rogers, R. R., Butler, C., Cook, A. L., and Harper, D. B.: Comparison of mixed layer heights from airborne high spectral resolution lidar, ground-based measurements, and the WRFChem model during CalNex and CARES, Atmos. Chem. Phys., 14, 5547-5560, doi:10.5194/acp-14-5547-2014, 2014.

Schäfer, K., Emeis, S., Höß, M., Friedl, R., Münkel, C., and Suppan, P.: Comparison of continuous detection of mixing layer heights by ceilometer with radiosonde observations, SPIE, 817707 , 2011.

Seibert, P., Beyrich, F., Gryning, S. E., Joffre, S., Rasmussen, A., and Tercier, P.: Review and intercomparison of operational methods for the determination of the mixing height, Atmos. Environ., 34, 1001-1027, 2000.

Steyn, D. G., Baldi, M., and Hoff, R. M.: The Detection of Mixed Layer Depth and Entrainment Zone Thickness from Lidar Backscatter Profiles, J. Atmos. Ocean. Tech., 16, 953-959, 1999.

Stull, R. B.: An Introduction to Boundary Layer Meteorology, Kluwer Academic, 1988.

Toledo, D., Córdoba-Jabonero, C., and Gil-Ojeda, M.: Cluster Analysis: A New Approach Applied to Lidar Measurements for Atmospheric Boundary Layer Height Estimation, J. Atmos. Ocean. Tech., 31, 422-436, doi:10.1175/JTECH-D-12-00253.1, 2014.

Uzan, L., Egert, S., and Alpert, P.: Ceilometer evaluation of the eastern Mediterranean summer boundary layer height - first study of two Israeli sites, Atmos. Meas. Tech., 9, 4387-4398, doi:10.5194/amt-9-4387-2016, 2016.

Vaisala Oyj: BL-Matlab User's Guide v0.98, Vaisala Oyj, Helsinki, Finland, 2011.

Weitkamp, C.: Lidar: Range-Resolved Optical Remote Sensing, Optical Sciences Series, Springer, 2005.

Wiegner, M. and Gasteiger, J.: Correction of water vapor absorption for aerosol remote sensing with ceilometers, Atmos. Meas. Tech., 8, 3971-3984, doi:10.5194/amt-8-3971-2015, 2015. 